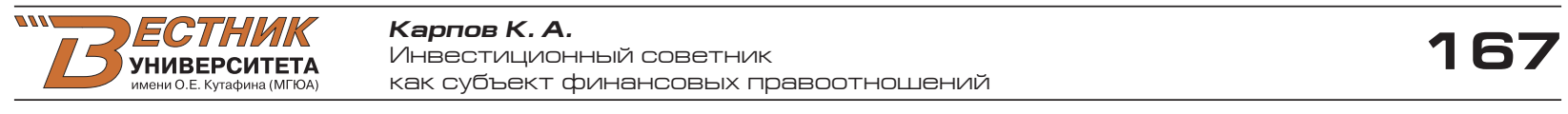

\section{Инвестиционный советник как субъект финансовых правоотношений}

\begin{abstract}
Аннотация. Статья посвящена рассмотрению правового положения инвестиционного советника как субъекта финансовых правоотношений. Уделяется внимание генезису и развитию данного института как в России, так и в зарубежных юрисдикциях. В работе приводятся различные точки зрения по вопросу определения понятия «финансовая услуга». Автор перечисляет аргументы, подтверждающие, что инвестиционный советник обладает финансово-правовым статусом. В работе выражается авторское мнение, что дальнейшее развитие указанного института позволит улучшить не только инвестиционный климат в нашей стране, но и отношение граждан РФ к рынку ценных бумаг.

Ключевые слова: инвестиционный советник, финансовые правоотношения, профрессиональный участник рынка ценных бумаг, фринансовая услуга, фрондовая биржа, розничный инвестор, инвестиционный профиль, финансовый рынок, Банк России.
\end{abstract}

\section{DOI: 10.17803/2311-5998.2021.85.9.167-177}

K. A. KARPOV,

postgraduate student of Department in Financial Law of Kutafin Moscow State Law University (MSAL)

karpov.moscow@gmail.com

9, ul. Sadovaya-Kudrinskaya, Moscow, Russia, 125993

\title{
Investment adviser as a subject of the financial legal relations
}

\begin{abstract}
This article is devoted to the consideration of the legal status of an investment advisor as a subject of financial legal relations. Attention is paid to the genesis and development of this institution, both in Russia and in foreign jurisdictions. The paper provides various points of view on the definition of the concept of "financial service". The author lists the arguments confirming that the investment advisor has financial and legal status. The paper expresses the author's opinion that the further development of this institution will improve not only the investment climate in our country, but also the attitude of Russian citizens to the securities market.

Keywords: investment advisor, financial legal relations, professional participant of the securities market, financial service, stock exchange, retail investor, investment profile, financial market, Bank of Russia.
\end{abstract}




\section{Введение}

С развитием рыночных отношений в Российской Федерации можно наблюдать существенную эволюцию рынка ценных бумаг. Это утверждение может быть подтверждено соответствующей официальной статистикой фондовых бирж России. Так, с конца 2017 г. по март 2021 г. количество розничных инвесторов, зарегистрированных на ПАО «Московская биржа» увеличилось многократно: с 1893 678 фиизиеских лиц в декабре 2017 г. до 17986457 к марту 2021 г. ${ }^{1}$

Указанная тенденция связана со значительным понижением ключевой ставки Центральным банком РФ в 2020 г., а также с введением с 1 января 2021 г. 13 \%-ного НДФЛ на процентные доходы со вкладов более чем 1 млн российских рублей, как и на доходы со вкладов, процентная ставка которых превышает за отчетный период ${ }^{2}$ ключевую ставку Банка России ${ }^{3}$. Кроме того, на увеличение количества уникальных инвесторов повлияла и общедоступность электронных платформ - все действия, включая подписание договора о брокерском обслуживании, могут быть совершены дистанционно.

Целесообразно заметить, что большинство розничных инвесторов не обладает специальными знаниями по экономике, и в частности по регулированию фрондовых рынков. Следовательно, им необходимо взаимодействовать с лицами, которые могут оказать соответствующие консультационные услуги, касающиеся купли-продажи ценных бумаг. В настоящее время такими лицами являются инвестиционные советники.

\section{Генезис института инвестиционного советника}

В Российской империи не существовало обособленного института инвестиционного советника. Услуги по инвестиционному консультированию оказывались сотрудниками банков ${ }^{4}$, т.е. не существовали централизованные организации, которые занимались бы данным видом деятельности. Заметим, что в большинстве акционерных обществ работали специальные сотрудники - консультанты по вопросам купли-продажи ценных бумаг 5 .

1 Статистика по клиентам // URL: https://www.moex.com/s719 (дата обращения: 17.04.2021).

2 Письмо Министерства финансов РФ от 20.11.2020 № 03-04-07/101287 // СПС «КонсультантПлюс».

3 ФНС России разъяснила особенности порядка обложения НДФЛ процентов, полученных по вкладам в банках // URL: https://www.nalog.ru/rn77/news/activities_fts/10237437/ (дата обращения: 14.01.2021).

4 К примеру, писатель М. Е. Салтыков-Щедрин обращался к работнику банкирского дома Гинцбургов С. Барацу по вопросу консультирования по ценным бумагам. Так, писатель планировал продать акции одной компании и купить акции компании «Московская-Рязанская дорога». См.: Салтыков-Щедрин М. Е. Собрание сочинений : в 20 т. М., 1965-1977. T. 20 : Письма. С. 218.

5 Мошенский С. З. Рынок ценных бумаг Российской империи. London : Xlibris, 2014. C. 21-22. 


\begin{tabular}{|c|c|}
\hline 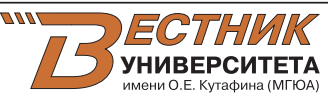 & $\begin{array}{l}\text { Карпов К. А. } \\
\text { ИнвестИЦИонный советник } \\
\text { Как субъект финансовых правоОтношений }\end{array}$ \\
\hline
\end{tabular}

В советский период потребности в институте инвестиционных советников не было, так как в то время в стране не существовал фондовый рынок. При командно-административной экономике подобные явления подвергались жесткой критике и пресекались. Государство ограничивалось выпусками займов, которые приобретало население страны. Так, о выпусках облигаций советским правительством М. А. Гурвич писал следующее: «Важным источником доходов являются добровольные взносы населения. Систематический рост материального благосостояния трудящихся на основе хозяйственного развития страны позволяет привлечь в значительных размерах сбережения самих трудящихся на нужды социалистического строительства» ${ }^{6}$.

В связи с развитием и одновременно усложнением финансовых продуктов в мире возникла острая необходимость в специальных субъектах - инвестиционных советниках. Конкуренция вынудила фринансовые организации предлагать частным клиентам все более узкоспециализированные, а также сложные финансовые инструменты. К примеру, в Великобритании институт независимого фринансового советника (independent financial adviser) существует с момента принятия Закона о фринансовых услугах (Financial services Act) ${ }^{7}$ в 1986 г., который регламентировал деятельность независимых советников, предоставлявших услуги розничным клиентам по покупке ценных бумаг, ипотеке и страхованию домов и автомобилей ${ }^{8}$.

Также в США упомянутый институт получил свое легальное закрепление в 1940 г. — с момента принятия Закона об инвестиционных советниках (Investment advisers Act of 1940) ${ }^{9}$. В соответствии с законодательством США о рынке ценных бумаг инвестиционными советниками могут быть как организации, так и физические лица, обладающие специальными знаниями, образованием и опытом в данной сорере. Также инвестиционные советники должны пройти процедуру регистрации в Комиссии по ценным бумагам и биржам (Securities and exchange commission - SEC). Важно упомянуть, что консультанты, имеющие под управлением активы на сумму не менее 100 млн долларов США, регистрируются в SEC. Другие инвестиционные консультанты проходят процедуру регистрации в штате, в котором данное лицо осуществляет свой основной вид деятельности.

В нашей стране институт инвестиционного советника в современном его понимании появился только в 90-х гг. XX в. Основным документом, определившим на этом этапе состав участников рынка ценных бумаг и регламентировавшим их деятельность, было постановление Правительства РСФСР от 28.12.1991 № 78 «Об утверждении Положения о выпуске и обращении ценных бумаг и фондовых биржах в РСФСР» ${ }^{10}$ (далее - Положение).

6 Гурвич М. А. Советское финансовое право. М. : Госюриздат, 1954. С. 244.

7 Financial services Act // URL: https://www.legislation.gov.uk/ukpga/1986/60/pdfs/ ukpga_19860060_en.pdf (дата обращения: 27.03.2021).

8 Choosing a financial adviser // URL: https://www.moneyadviceservice.org.uk/en/articles/ choosing-a-financial-adviser (дата обращения: 23.03.2021).

9 Investmet advisers Act of 1940. As Amended Through P. L. 115-417, Enacted January 03, 2019.

10 Положение о выпуске и обращении ценных бумаг и фондовых биржах в РСФСР (утв. постановлением Правительства РСФСР от 28.12.1991 № 78) // Финансовая газета. 1992. № 5. 
Согласно п. 14 Положения учреждались инвестиционные институты — юридические лица, созданные в любой допускаемой Законом РСФСР от 25.12.1990 № 445-1 «О предприятиях и предпринимательской деятельности» организационно-правовой форме. Эти организации могли выступать инвестиционными консультантами. Ими же могли быть также и физические лица. Деятельность указанных субъектов заключалась в оказании консультационных услуг по вопросам выпуска и обращения ценных бумаг на территории нашего государства.

Впоследствии был подписан Указ Президента РФ от 04.11.1994 № 2063 «О мерах по государственному регулированию рынка ценных бумаг в Российской Федерации» ${ }^{11}$. Впервые в России были легально закреплены понятие «профрессиональный участник рынка ценных бумаг» и виды предпринимательской деятельности на фондовом рынке (брокерская, дилерская, деятельность по ведению и хранению реестра акционеров, депозитарная, расчетно-клиринговая по ценным бумагам и по организации торговли ценными бумагами).

В дальнейшем в Федеральном законе от 22.04.1996 № 39-Ф3 «О рынке ценных бумаг» были закреплены необходимые требования к профессиональным участникам рынка ценных бумаг ${ }^{12}$.

Исходя из положений ст. 2 данного Федерального закона под профессиональным участником рынка ценных бумаг понимаются юридические лица, которые созданы в соответствии с законодательством РФ и осуществляют виды деятельности, указанные в ст. 3-5, 7, 8 (брокеры, дилеры, управляющие, депозитарии, держатели реестра ценных бумаг) и иные лица, указанные в ст. 6.1 (инвестиционные советники).

\section{Понятие финансовой услуги}

Необходимо перейти к вопросу определения понятия финансовой услуги. Заметим, что существуют различные мнения ученых и дифференцированные позиции законодателя и судебной практики.

Так, в современной России под финансовой услугой в ст. 142.1 Налогового кодекса РФ понимаются услуги, «связанные с привлечением от клиентов и размещением организациями финансового рынка денежных средств или иных финансовых активов для хранения, управления, инвестирования и (или) осуществления иных сделок в интересах клиента либо прямо или косвенно за счет клиента» ${ }^{13}$. Практически сходное понятие финансовой услуги упоминается в ст. 4 Федерального закона от 26.07.2006 № 135-Ф3 «О защите конкуренции» ${ }^{14}$.

В судебной практике содержится уже иное, более широкое определение фринансовой услуги. В постановлении Пленума Верховного Суда РФ от 28.06.2012

11 Указ Президента РФ от 04.11.1994 № 2063 «О мерах по государственному регулированию рынка ценных бумаг в Российской Федерации» // Российская газета. 10.11. 1994. № 217.

12 Федеральный закон от 22.04.1996 № 39-Ф3 «О рынке ценных бумаг» // Российская газета. 25.04.1996. № 79.

${ }^{13}$ Налоговый кодекс РФ // СЗ РФ. № 31. 1998. Ст. 3824.

14 С3 РФ. № 31. Ст. 3434. 


\begin{tabular}{|c|c|}
\hline ПS) & $\begin{array}{l}\text { Карпов К. А. } \\
\text { ИнвестИЦИонный советник } \\
\text { Как субъект финансовых правоотношений }\end{array}$ \\
\hline
\end{tabular}

№ 17 «О рассмотрении судами гражданских дел по спорам о защите прав потребителей» указано, что «под фринансовой услугой следует понимать услугу, оказываемую фризическому лицу в связи с предоставлением, привлечением и (или) размещением денежных средств и их эквивалентов, выступающих в качестве самостоятельных объектов гражданских прав (предоставление кредитов (займов), открытие и ведение текущих и иных банковских счетов, привлечение банковских вкладов (депозитов), обслуживание банковских карт, ломбардные операции и т.п.)» ${ }^{15}$.

Понятие финансовой услуги было рассмотрено в том числе в трудах ученых правоведов и экономистов. Так, представитель экономической науки Я. М. Миркин под финансовой услугой понимает «комплекс действий, осуществляемых фринансовыми посредниками по привлечению и размещению денежных ресурсов на фринансовых рынках на основе использования фринансовых инструментов» ${ }^{16}$. При этом выделяются следующие виды этих услуг:

1) услуги финнансовых институтов по непосредственному перераспределению денежных ресурсов путем совершения сделок на фринансовых рынках;

2) услуги по осуществлению операций на финансовых рынках;

3) услуги по организации и регулированию фринансовых рынков;

4) обеспечивающие функции.

Другое мнение содержится в трудах ученого-юриста Н. Г. Семилютиной. Она считает, что финансовой услугой является только та, которая оказывается профессиональным участником фринансового рынка, обладающим разрешением (лицензией) уполномоченного регулирующего органа ${ }^{17}$. Также она рассматривает понятия «финансовая услуга» и «инвестиционная услуга» как тождественные ${ }^{18}$. Однако А. Г. Гузнов указывает на то, что «вне этого контекста остается, к примеру, страховой рынок как относительно обособленная часть финансового рынка» ${ }^{19}$.

Представитель науки гражданского права Е. В. Тужилова-Орданская под финансовой услугой понимает деятельность, связанную с привлечением и размещением денежных средств как фризических, так и юридических лиц, осуществляемую специальным субъектом рынка фринансовых услуг, фринансовой организацией, основанную на односторонних сделках или группе договоров, направленную на удовлетворение имущественных потребностей субъектов прав ${ }^{20}$.

15 Постановление Пленума Верховного Суда РФ от 28.06.2012 № 17 «О рассмотрении судами гражданских дел по спорам о защите прав потребителей» // Российская газета. 2012. № 156 .

16 Миркин Я. М. Финансовое будущее России: экстремумы, бумы, системные риски. М. : Geleos publishing house ; Кэпитал Трейд Компани, 2011. С. 467.

17 Семилютина Н. Г. Российский рынок фринансовых услуг (формирование правовой модели). Wolters Kluwer Russia, 2005. С. 37.

18 Семилютина Н. Г. Формирование правовой модели российского рынка финансовых услуг : дис. ... д-ра юрид. наук. М., 2005. С. 15.

19 Гузнов А. Г. Финансово-правовое регулирование финансового рынка в Российской Федерации : дис. ... д-ра юрид. наук. М., 2016. С. 29.

20 Тужилова-Орданская Е. В. Понятие финансовой услуги // Правовое государство: теория и практика. 2014. № 1 (35). С. 152.

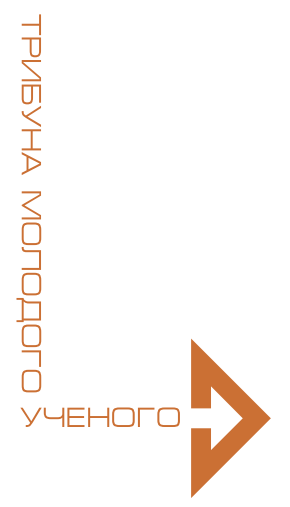


Н. Г. Семилютина также считает, что финнансовая услуга оказывается только профрессиональными участниками рынка ценных бумаг (при наличии разрешения государственного органа), осуществляется на основании договора и направлена на размещение денежных средств, исключительно свободных, на основании срочности, платности и возвратности ${ }^{21}$.

Р. О. Халфрина замечала, что фринансовые акты, являясь одним из видов административных актов, служат основанием возникновения и развития финансовых правоотношений ${ }^{22}$. Эти акты издаются специализированными финансовыми органами публичной власти, в данном случае - Банком России.

\section{Финансово-правовое регулирование деятельности инвестиционного советника}

В 2017 г. в Федеральный закон от 22.04.1996 № 39-Ф3 «О рынке ценных бумаг» были введены нормы, закрепившие основы правового положения инвестиционного советника ${ }^{23}$.

Важно заметить, что первоначально при подготовке поправок в действующее законодательство деятельность по инвестиционному консультированию обозначалась этимологически сходным понятием - «финансовое консультирование». Однако от данного предложения было решено отказаться, так как в ст. 2 Федерального закона «О рынке ценных бумаг» уже используется практически сходное понятие, а именно: «финансовый консультант на рынке ценных бумаг». Под ним понимается юридическое лицо, имеющее лицензию на осуществление брокерской и (или) дилерской деятельности на рынке ценных бумаг, оказывающее эмитенту услуги по подготовке проспекта ценных бумаг. Из легального определения финансового консультанта следует, что его деятельность ограничена исключительно подготовительными работами по эмиссии ценных бумаг.

Следует подчеркнуть, что в современной России существует развитая индустрия финансовых советников. Как отмечает вице-президент Национальной ассоциации участников фондового рынка (НАУФОР) Е. Е. Андреева, финансовый советник занимается различными видами деятельности, не имея какого-либо разрешения (лицензии) контрольно-надзорных органов, в то время как инвестиционный советник осуществляет деятельность по оказанию услуг своим клиентам только по вопросам инвестиций, формированию портфреля из ценных бумаг и деривативов на основе его внесения в соответствующий реестр Банка России ${ }^{24}$.

${ }^{21}$ Тужилова-Орданская Е. В. Указ. соч. С. 15.

22 Халфина Р. О. Общее учение о правоотношении. М. : Юрид. лит., 1974. С. 293-294.

${ }^{23}$ Федеральный закон от 20.12.2017 № 397-Ф3 «О внесении изменений в Федеральный закон "О рынке ценных бумаг" и статью 3 Федерального закона "О саморегулируемых организациях в сфере финансового рынка"» // Российская газета. 22.12.2017. № 291.

${ }^{24}$ Екатерина Андреева: «Спрашивайте в лоб: “Ты финансовый советник или ты инвестиционный консультант?"» // URL: https://www.finversia.ru/interview/ekaterina-andreevasprashivaite-v-lob-ty-finansovyi-sovetnik-ili-ty-investitsionnyi-konsultant-67321 (дата обращения: 26.11.2020). 


\begin{tabular}{|c|c|}
\hline П & $\begin{array}{l}\text { Карпов К. А. } \\
\text { ИнвестИЦИОнньй советник } \\
\text { Как субъект финансовых правоотношений }\end{array}$ \\
\hline
\end{tabular}

Финансовый консалтинг существовал в России и ранее, но не был урегулирован - участники могли руководствоваться общими нормами Гражданского кодекса $Р \Phi^{25}$. Появились правовые основания предоставления инвестиционными советниками соответствующих фринансовых услуг (консультаций). На законодательном уровне было введено в оборот официальное наименование данного вида деятельности и профессии - инвестиционный советник. Были определены соответствующие требования, а также регламентирована ответственность.

Следовательно, можно констатировать следующее: сфера инвестиционного консультирования попала под контроль Банка России, который издает соответствующие нормативные акты. Более того, оказываемые инвестиционным советником консультации - фринансовые услуги осуществляются им исключительно на основании санкции Центрального банка РФ посредством внесения в специально созданный мегарегулятором реестр сведений об инвестиционном советнике.

Уделим внимание требованиям, предъявляемым к инвестиционному советнику. Они закреплены в различных нормативных правовых актах, нормативных актах Банка России, а также в иных документах ${ }^{26}$. В соответствии с ч. 2 ст. 6.1 Федерального закона «О рынке ценных бумаг» под инвестиционным советником понимается профессиональный участник рынка ценных бумаг, осуществляющий деятельность по инвестиционному консультированию.

Только данные лица могут использовать слова «инвестиционный советник» и производные от них слова и словосочетания. Это требование является

${ }^{25}$ Алексеева И. А., Овчинникова К. А. Эволюция профессиональных участников на российском рынке ценных бумаг // Известия Байкальского государственного университета. 2019. T. 29. № 3. С. 421.

${ }^{26}$ См.: Федеральный закон «О рынке ценных бумаг» ; Федеральный закон от 13.07.2015 № 223-Ф3 «О саморегулируемых организациях в сфере фринансового рынка» // СЗ РФ. 2007. № 49 Ст. 6076 ; указания Банка России от 02.11.2018 № 4956-У «О требованиях к инвестиционным советникам» // Вестник Банка России. 2019. № 10 ; от 15.11.2018 № 4970-У «О порядке и сроках принятия Банком России решения о внесении (об отказе во внесении) сведений о юридическом лице (индивидуальном предпринимателе) в единый реестр инвестиционных советников, перечне документов, на основании которых Банк России принимает решение о внесении (об отказе во внесении) сведений о юридическом лице (индивидуальном предпринимателе) в единый реестр инвестиционных советников, форме заявления о внесении сведений о юридическом лице (индивидуальном предпринимателе) в единый реестр инвестиционных советников, основаниях для принятия Банком России решения об отказе во внесении сведений о юридическом лице (индивидуальном предпринимателе) в единый реестр инвестиционных советников и порядке ведения Банком России единого реестра инвестиционных советников» // Там же. 2018. № 88 ; от 17.12.2018 № 5014-У «О порядке определения инвестиционного профиля клиента инвестиционного советника, о требованиях к форме предоставления индивидуальной инвестиционной рекомендации и к осуществлению деятельности по инвестиционному консультированию» // Там же. 2019. № 13 ; Положение о Комитете по стандартам по деятельности инвестиционных советников при Банке России (в ред. от 20.07.2020) // СПС «КонсультантПлюс»; письмо Департамента налоговой и таможенной политики Минфина России от 03.03.2020 № 03-07-07/15706 // Там же. 
обоснованным, так как в настоящее время недобросовестными лицами посредством использования средств массовой информации, включая информационнотелекоммуникационную сеть Интернет, большинство розничных инвесторов вводится в заблуждение представителями так называемой «индустрии советников» (фринансовых советников, консультантов и т.д.).

Де-юре они не являются инвестиционными советниками, так как большинство из них не соответствует требованиям, предъявляемым к данному виду профессиональных участников рынка ценных бумаг, а также они не внесены в соответствующий реестр Банка России. Де-фракто указанные субъекты, не пройдя регистрацию в качестве индивидуального предпринимателя или юридического лица, оказывают инвестиционные и иные консультационные услуги физическим и юридическим лицам даже без заключения договоров или иных соглашений.

В то же время инвестиционный советник обязан осуществлять свою деятельность, основываясь на договоре, заключенном с его клиентом. Также немаловажно, что инвестиционным советником может быть как индивидуальный предприниматель, так и юридическое лицо, которое платит соответствующие налоги и страховые взносы. В соответствии с указанием Банка России от 02.11.2018 № 4956-У «О требованиях к инвестиционным советникам» ${ }^{27}$ инвестиционный советник, который является индивидуальным предпринимателем, должен иметь высшее образование и соответствующий профессиональный опыт по совершению сделок на фрондовых биржах.

В нормативном акте Банка России есть указание на специальное требование - наличие у инвестиционного советника специального образования: свидетельства о квалификации, международных сертификатов (International certificate in advanced wealth management) и др. При наличии таких документов практический опыт совершения сделок на фондовых биржах не требуется. Если инвестиционным советником является юридическое лицо, то оно должно иметь как минимум одного сотрудника, который будет осуществлять деятельность по инвестиционному консультированию. Также заметим, что такие организации имеют право совмещать свою деятельность с иными видами профессиональной деятельности на рынке ценных бумаг и деятельностью кредитной организации.

Более того, в соответствии со ст. 76.1 Федерального закона от 10.07.2002 № 86-Ф3 «О Центральном банке Российской Федерации (Банке России)» инвестиционный советник является некредитной финансовой организацией, так как осуществляет свою деятельность в качестве профессионального участника рынка ценных бумаг ${ }^{28}$.

Следовательно, в соответствии с инструкцией Банка России от 15 января 2020 г. № 202-И «О порядке проведения Банком России проверок поднадзорных лиц» ${ }^{29}$ мегарегулятор имеет право проводить проверки в отношении осуществляемой инвестиционным советником деятельности.

${ }^{27}$ Вестник Банка России. 2019. № 10.

28 Федеральный закон от 10.07.2002 № 86-Ф3 «О Центральном банке Российской Федерации (Банке России)» // Российская газета. 2002. № 127.

29 Инструкция Банка России от 15.01.2020 № 202-И «О порядке проведения Банком России проверок поднадзорных лиц» // Вестник Банка России. 2020. № 32. 


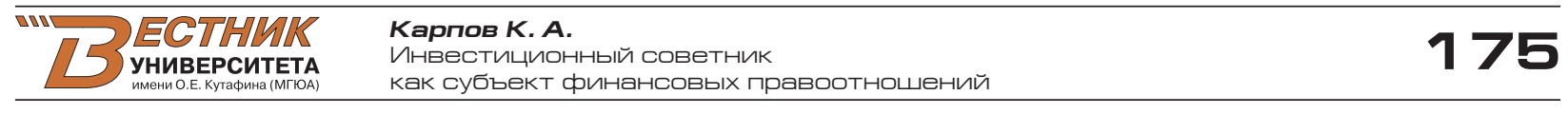

В современной России инвестиционными советниками являются крупные брокеры и кредитные организации: АО «Финам», АО «Сбербанк КИБ» и др. На апрель 2021 г. в реестре Банка России зарегистрировано 102 инвестиционных советника, 3 инвестиционных советника были исключены из реестра ${ }^{30}$.

Основным видом деятельности по инвестиционному консультированию является оказание консультационных услуг в отношении ценных бумаг, сделок с ними и (или) заключения договоров, являющихся производными финансовыми инструментами (деривативами), путем предоставления индивидуальных инвестиционных рекомендаций. Инвестиционный советник обязан совершать эти действия разумно, добросовестно и действовать в интересах клиента.

Для дополнительной защиты клиента инвестиционный советник обязан вести его инвестиционный профиль. В профиле должна содержаться информация о возрасте клиента - фризического лица, его образовании, а также иная информация. Если клиентом является организация, то необходимо запросить размер ее активов и другую информацию, касающуюся хозяйственной деятельности данной компании. Также все рекомендации могут быть предоставлены в устной фрорме (с обязательным ведением аудиозаписи), в форме документа на бумажном носителе или в форме электронного документа, подписанного электронной подписью.

\section{Контроль профильного комитета Банка России и СРО за деятельностью инвестиционных советников}

Деятельность по инвестиционному консультированию подлежит контролю со стороны Банка России и саморегулируемых организаций. Одно из важнейших требований, предъявляемых к инвестиционным советникам, заключается в их членстве в СРО. Данные организации имеют право устанавливать дополнительные требования (стандарты) к деятельности инвестиционных советников - членов данного СРО. Так, НАУФОР разработаны два стандарта: базовый и внутренний ${ }^{31}$.

В указанных стандартах есть ссылка на то, что инвестиционный советник оказывает именно финансовые услуги. Другое СРО - Национальная финансовая организация (НФА) также приняла Базовый стандарт совершения инвестиционным советником операций на финансовом рынке ${ }^{32}$. В этом стандарте регламентируются дополнительные права и обязанности инвестиционного советника при предоставлении им консультаций (услуг) своим клиентам и контроль над ним со стороны СРО.

Акцентируем внимание на том, что с 2019 г. на постоянной основе действует Комитет по стандартам по деятельности инвестиционных советников при Банке

${ }^{30}$ Единый реестр инвестиционных советников // URL: https://www.cbr.ru/registries/?cf. search=единый+реестр+инвестиционных+советников\&cf.tagid=\&cf.date.time=any\&cf.date. datefrom=\&cf.date.dateto= (дата обращения: 17.04.2021).

${ }^{31}$ Для инвестиционных советников // URL: https://naufor.ru/tree.asp?n=16044 (дата обращения: 27.11.2020).

32 Базовый стандарт совершения инвестиционным советником операций на финансовом рынке // URL: https://new.nfa.ru/upload/iblock/b13/Bazovyy-standart_21112019.pdf (дата обращения: 27.11.2020). 
России (далее - Комитет). Правовой статус этого органа мегарегулятора закреплен в Положении о Комитете по стандартам по деятельности инвестиционных советников при Банке России ${ }^{33}$.

Данный орган согласовывает базовые стандарты, разработанные СРО для инвестиционных советников, вырабатывает предложения о направлениях развития их деятельности. Также Комитет проводит экспертизу проектов нормативных правовых актов и нормативных актов Банка России по вопросам деятельности инвестиционных советников. Более того, данный орган осуществляет взаимодействие с образовательными, научными и международными организациями и выполняет также и иные функции. В состав органа входят сотрудники Банка России и представители СРО, количество которых не может быть меньше, чем две трети от списочного состава членов Комитета (общее количество - не более 25 человек).

\section{Заключение}

В ходе проведенного нами исследования было выявлено, что консультационная деятельность на рынке ценных бумаг является важнейшим элементом функционирования и развития эффрективного фрондового рынка. Всесторонне был исследован вопрос об определении финансовой услуги и ее оказании инвестиционным советником при консультировании своих клиентов. Статус данного профессионального участника рынка ценных бумаг основан на различных нормативных правовых актах, большинство из которых относятся к источникам финансового права.

Надзор за деятельностью инвестиционных советников осуществляется Центральным банком РФ, являющимся ключевым субъектом фринансово-правовых отношений, а также специально созданным Комитетом мегарегулятора ${ }^{34}$ и СРО в сорере финансового рынка.

Следовательно, можно сделать вывод о том, что инвестиционный советник является субъектом фринансовых правоотношений. Считаем, что дальнейшее развитие данного института позволит улучшить инвестиционный климат и доверие розничных инвесторов к нашему рынку, что будет способствовать увеличению количества данных инвесторов ${ }^{35}$. Это также положительно скажется на повышении ликвидности российского рынка ценных бумаг и его статусе в мире.

33 Положение о Комитете по стандартам по деятельности инвестиционных советников при Банке России (ред. от 20.07.2020).

34 Рождественская T. Э. Банк России как мегарегулятор на финансовом рынке: особенности правового статуса // Вестник Университета имени О.Е. Кутафина (МГЮА). 2014. № 4. C. $63-64$.

35 Сбербанк в 2023 году планирует нарастить долю инвестиций граждан с 13 \% до 23 \% // URL: https://tass.ru/ekonomika/10133253 (дата обращения: 30.11.2020). 


\section{БИБЛИОГРАФИЯ}

1. Алексеева И. А., Овчинникова К. А. Эволюция профессиональных участников на российском рынке ценных бумаг // Известия Байкальского государственного университета. — 2019. - Т. 29. - № 3.

2. Арзуманова Л. Л., Рождественская Т. Э., Белова Л. Г., Костюк И. В., Ротко С. В., Холкина М. Г., Рогалева М. А., Тимошенко Д. А. Комментарий к Федеральному закону от 22 апреля 1996 г. № 39-Ф3 «О рынке ценных бумаг». 2-е изд., испр. и доп. // СПС «Гарант», 2020.

3. Гузнов А. Г. Финансово-правовое регулирование финансового рынка в Российской Федерации : дис. ... д-ра юрид. наук. - М., 2016. - 493 с.

4. Гурвич М. А. Советское фринансовое право. - М. : Госюриздат, 1954. - 320 с.

5. Миркин Я. М. Финансовое будущее России: экстремумы, бумы, системные риски. - М. : Geleos publishing house ; Кэпитал трейд компани, 2011. — 479 c.

6. Мошенский С. 3. Рынок ценных бумаг Российской империи. - London : Xlibris, 2014. - 690 c.

7. Рожденственская T. Э. Банк России как мегарегулятор на финансовом рынке: особенности правового статуса // Вестник Университета имени О.Е. Кутафина (МГЮА). - 2014. — № 4.

8. Салтыков-Щедрин М. Е. Собрание сочинений : в 20 т. - М., 1965-1977. — Т. 20 : Письма.

9. Семилютина Н. Г. Российский рынок фринансовых услуг (формирование правовой модели). - Wolters Kluwer Russia, 2005. - 336 с.

10. Семилютина Н. Г. Формирование правовой модели российского рынка финансовых услуг : дис. ... д-ра юрид. наук. - М., 2005. - 336 с.

11. Тужилова-Орданская Е. В. Понятие фринансовой услуги // Правовое государство: теория и практика. - 2014. — № 1 (35).

12. Халфрина Р. О. Общее учение о правоотношении. — М. : Юрид. лит., 1974. — $345 \mathrm{c}$. 